\title{
《京城日報』文学・文化叢書》全13巻
}

Bokyoung KIM(金普慶: Assistant Professor, Department of Japanese Studies, Korea National Open University)

西bokyoungkim@knou.ac.kr

(韓国) 韓国放送通信大学校日本学科助教授。日本近現代文学・日本映画専攻。主著に「アメリカ占 領期の性病管理政策之性教育映画：『花ある毒草』(1948) を中心に(『韓日軍事文化研究』第28号.

2019)、共著『日本の災難文学と文化』(ソウル：高麗大学校出版文化院, 2018)など。

\section{Keijo Nippo Literature and Culture Series (in 13 volumes)}

With the support of the National Research Foundation of Korea, the Global Institute for Japanese Studies at Korea University has translated a selection of the literary and cultural articles of Keijo Nippo. Six of the 12 volumes have already been published, and six more are scheduled for publication by the end of this year. Above all, this series is a collection of materials that provide a new perspective on the study of modern Japanese literature. In addition, the series illustrates the relationship between the Japanese and Korean literary circles during the colonial period by introducing Japanese novels by Korean writers published in Keijo Nippo.

Keywords Keijo Nippo(京城日報), Japanese Settlers in Colonial Korea(在朝日本人), Bilingual Writings (二言語創作) 
高麗大学校グローバル日本研究院は、韓国研究財団の土台研究事業(2015.9.1 2020.8.31)の支 援により、〈京城日報』収録文学資料DB構築〉事業を行うなかで発掘した『京城日報』の文学・文 化関連記事を選別して紹介する翻訳書(全13巻) と研究書となる《『京城日報』文学・文化叢書》を 企画し、全12巻のうち6巻は2020年5月すでに刊行され、後7巻も2021年1月に刊行を控えてい る。

当研究チームは刊行の辞において、日帝強占期朝鮮総督府の日本語機関誌だった『京城日報』 が、政治・経済・文化・社会知識・人的交流・文学・芸術・学問・植民地統治・法律・国策宣伝な どすべての植民地学知が日常的に流通する最大の空間」であったと説明している。そして『京城 日報』には、植民地朝鮮の学知を構成する重要な一角である文学と文化の実相がわかる、当時日 本の主要作家や在朝日本人作家、朝鮮人作家の作品と一般からの公募作が数多く掲載された。こ れら作品の素材とテーマには、日本文壇と植民地朝鮮の文壇との相互作用や植民政策が反映さ れたものが多く、また朝鮮の自然、人、文化を扱ったものもあった。

こうした『京城日報』に掲載された文学作品を、懸賞文学から、日本の主要作家の作品や朝鮮 の人・自然・文化などを扱った作品、朝鮮人作家の作品、探偵小説、児童文学、講談小説、映画 シナリオと評論まで、多様なジャンルを網羅的に収録し、植民地朝鮮における日本語文学の全 体像を把握できるようにしたというのが、この叢書の趣旨である。

また上記の文学作品が、朝鮮総督府の文化統治政策や「内鮮一体」のような同化政策の単なる プロパガンダに止まらないというのが本叢書の独自性のひとつである。在朝日本人の眼に映っ た朝鮮人の現実や、植民政策を実行した末端の軍属らの錯綜した感情など、それぞれの作品 は、植民地支配の主体たる上層部の日本人と支配される側であった朝鮮人という二項対立とは 別の視点から植民地下の朝鮮を描き出している。

さらに本叢書の学問的な貢献は次の点にもある。まず、本叢書は日本の近代文学研究に新た な視座を提供する資料集である。解題でも述べているように、『京城日報』は朝鮮半島で刊行さ れたものであったが、文芸、とりわけ長編小説は、主に日本文壇を代表する作家や新人作家、 在朝日本人作家の作品が掲載されていた。こうした作品のなかには、日本内地のメディアでも 同時掲載されたものを含め、初出が『京城日報』で、朝鮮の人や文化、風物などが作品の重要な 素材であり、その内容も植民地支配の文化政策と密接にかかわっているのが多い。しかしこう した事実は、これまで日本文学研究においてあまり重視されてこなかった。

たとえば、叢書に含まれている「天使」(1935.2-7)は、当時作家として最盛を誇っていた横 光利一(1898-1947)の小説である。この作品には、いわゆる「新感覚派」作家としての横光の文 学観がよく表れているだけでなく、朝鮮における日本の文化統治の文脈も見て取れる。これ までの研究においては「天使」が『京城日報』に発表されていたことが注目されてこなかった が、本叢書によって、今後の横光文学の研究に役立つ新たな視点が提供されるだろう。徳田 秋声(1872-1943)作の「曙」(1920.11-1921.7) と菊池寛(1888-1948) 作の「生活の虹」(1934.1-5)に ついても同じことがいえる。このように本叢書は、日本で確固たる位置を獲得していた作家 たちが植民地朝鮮の『京城日報』に書いた作品を翻訳・紹介することで、当時の日本文学の諸 
相、および植民地時代の「内地」文壇と朝鮮文壇との関係性をより立体的に捉えるための貴重 な資料集である。

次に、本叢書では、『京城日報』に掲載された朝鮮人作家の日本語小説も紹介している。今回 収録された植民地期の朝鮮人二言語作家である李石薰(1907-?)、秦學文(1894-1974)、李無影 (1908-1960)の日本語作品を通じて、当時日本で主流をなしていた文学思潮の影響はもちろん、 近代初期の韓国小説が日本語を媒介にして形成されていった経緯も明らかにすることができる と思われる。最後に、2021年1月刊行予定の研究書『植民地文化政治と『京城日報』：越境的文化研 究の可能性を問う』は、『京城日報』を中心に日本植民地支配下で各地域で営まれた日本語文学・ 文化の実情を東アジアの視覚で立体的に眺望し解釈することにより、植民地時期における日本 語文学・文化研究の可能性を問うという目的で企画されたものである。

本叢書が、植民地時代の朝鮮や日本近代文学の広範な理解にとってますます有益になってい くだろうことは疑いを容れない。また、研究者だけではなく、当時の韓国文学および日本文学 に興味を持っている一般の読者にとっても、さらなる興味を抱かせ、刺激するものである。

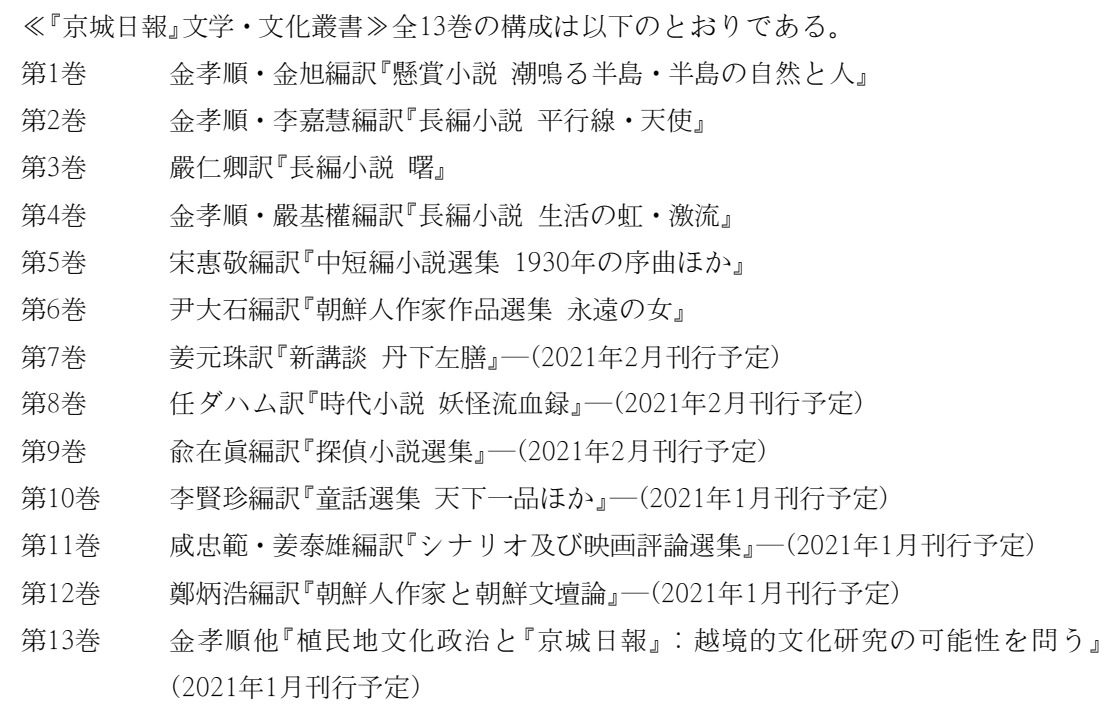



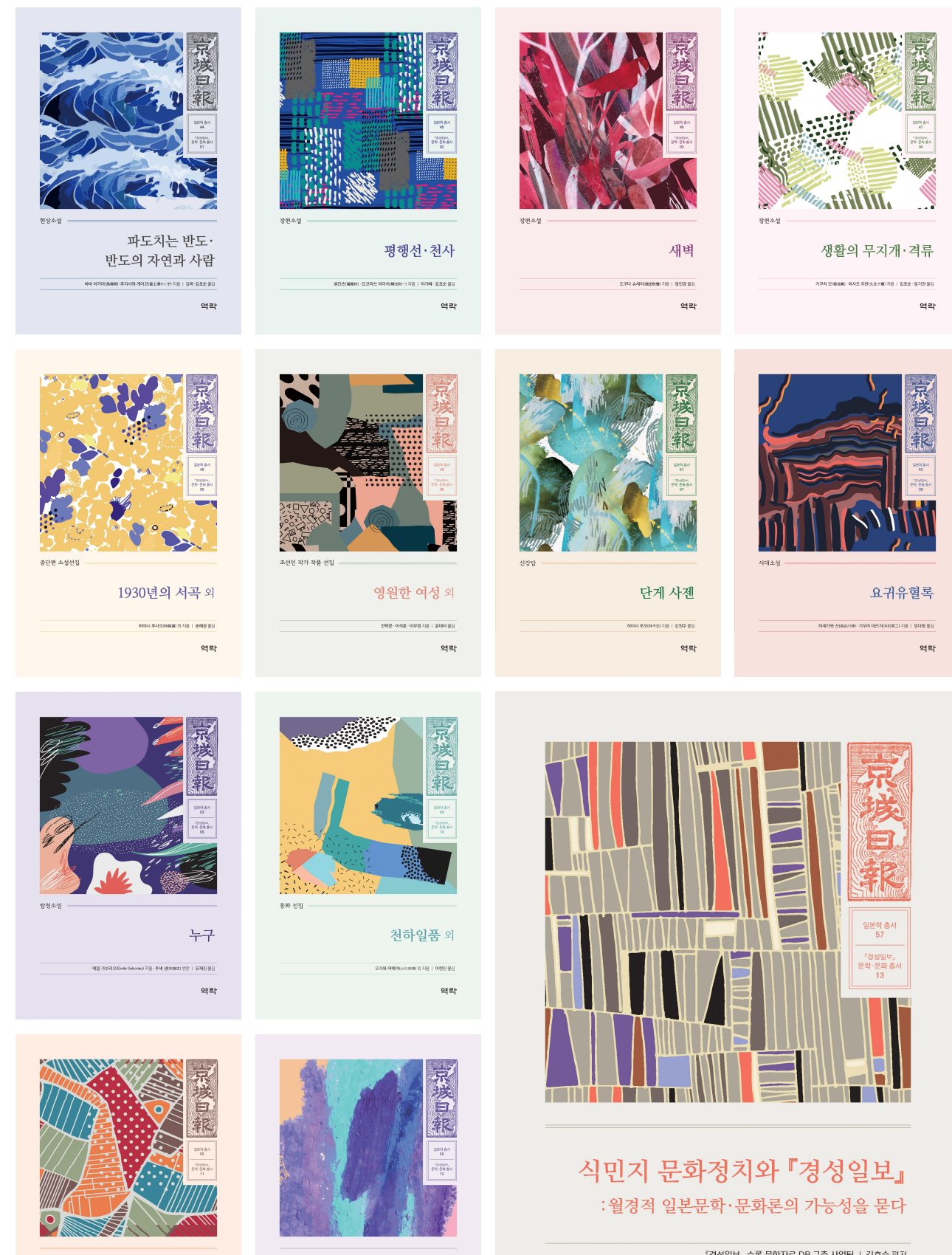

시나리오 및 영화 평론 선집
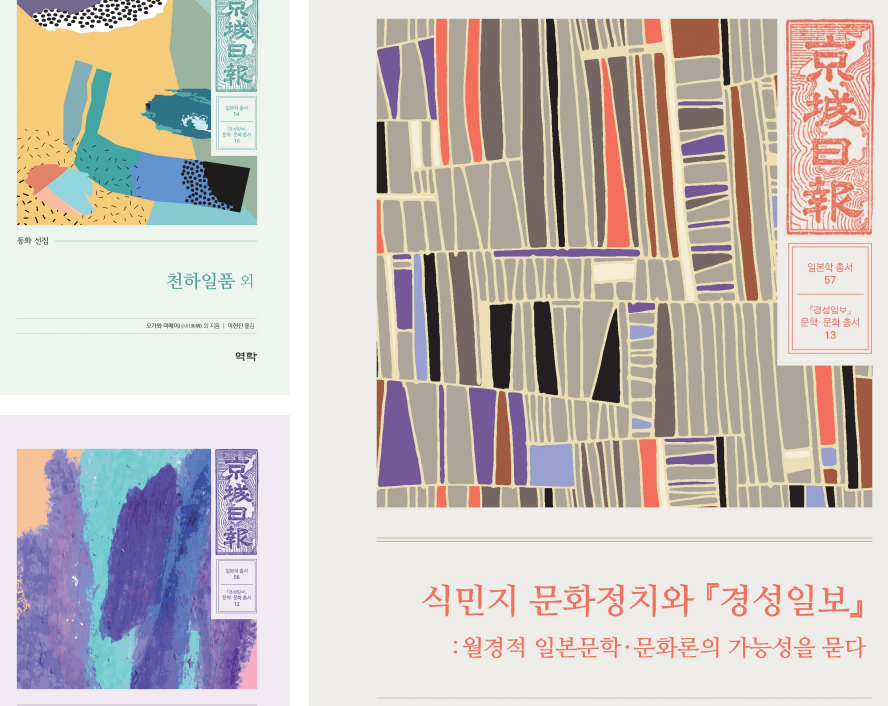

식민지 문화정치와『경성일보』 :월경적 일본문학·문화론의 가능성을 묻다

경성일보, 수록 문학자료 DB 구축 사업팀 | 김효순 펜저 조선인 작가와 조선문단론

역락

《『京城日報』文学·文化叢書》全13巻(2020.5-2021.2) 